\title{
Total Quality Management Revival and Six Sigma
}

\author{
Mona Jammal \\ Information Systems \\ Department \\ Faculty of Computing \& \\ Information Technology \\ King Abdulaziz University \\ Jeddah, Saudi Arabia
}

\author{
Shahad Khoja \\ Information Systems \\ Department \\ Faculty of Computing \& \\ Information Technology \\ King Abdulaziz University \\ Jeddah, Saudi Arabia
}

\author{
Azrilah Abd.Aziz, PhD \\ Information Systems \\ Department \\ Faculty of Computing \& \\ Information Technology \\ King Abdulaziz University \\ Jeddah, Saudi Arabia
}

\begin{abstract}
Total quality management is a management that is concerned with continuously improving the processes and functions within organization internally and externally simultaneously, in order to reach customer satisfaction. However, in the last decades there was concern that TQM has been less effective resulting from two external factors increasing the demands of good quality services from the customers, and the global market competitive pressure in addition to the internal factors. This paper attempts to expose the problems associated with TQM and how six sigma has helped in the renovation and rising of TQM in rational leadership, factual management, continues improvements, and employee partnership.
\end{abstract}

\section{Keywords}

Total Quality Management, Six Sigma, Factual Management, Rational Leadership, Continues Improvements, Employee Partnership, Total Quality Management Revival

\section{INTRODUCTION}

Total Quality Management (TQM) can be defined as an integrative approach that supports reaching of customer satisfaction by a range of tools and techniques that produce a higher quality of goods and services [1]. Another shorter definition for TQM is an approach for improving values delivered to the customers by enhancing organizational processes and systems [2]. One of the main purposes of the TQM is reaching the satisfaction of the customers and to allow companies gain a sustainable competitive advantage.

TQM consists of five basic principles which are: factual management, rational leadership, continuous improvements, employee partnership, and customer oriented approach.

Since the 1980s, there are a lot of important systems, or programs have been showed up for quality management such as: Six Sigma program, ISO 9000, and Reengineering. The popularity of the Six Sigma and many other concepts have been increased and a lot of organizations have transformed their strategies to follow these concepts. Pande support this view of point and states that the TQM in early 1990 was visible more than these days due to some reasons [3]. In this paper, we will illustrate what are the reasons behind TQM declines in interest, also, how it may recovered under another concept which is the Six Sigma.

\section{LITERATURE REVIEW}

Khandekar and Sulakhe mentioned that the TQM was a choice of the managers for approximately two decades [4]. However, in the beginning and mid of 1990, articles and people began to ask about the value and effectiveness of the TQM for number of organizations which results to a declines in using this concept. The authors stated that the usage of the
TQM declined due to: excessive bureaucracy, focus on internal processes, avoidance of genuine organizational reform, faddism which means an inclination for adopting a phenomena that is taken up with great enthusiasm for a brief period of time, and lack of innovation within the corporate culture. They suggested that the TQM can be revealed by the Six Sigma. They presented the emergence of the Six Sigma by enhancing the elevated employee involvement and how the employees can be trained, strong customer focus, and factual management.

Udayai and Kumar [2] discussed in their paper how the Six Sigma can help a hospital to manage more patients to gain more revenue and the patients' satisfaction. They focused on removing the delay in discharging the patients by applying the six sigma approach and observing the hospital's calls and observing mean time against Upper Specification Limit (USL) of the discharge process. They also draw a root cause analysis to help visually mapping the drivers of the variability in the process. Based on the root cause diagram, they suggest some of the actions for improving the process.

Revere and Black [5] wanted to reduce the medication errors by using Six Sigma in the hospital TQM plan. They presented a framework of integrating Six Sigma approach with TQM for a hospital and how the Six Sigma allows detailed root-cause analysis that uses a concurrent approach rather than the retrospective complaint approach typical with TQM. Furthermore, Six Sigma data can be used to identify improvement opportunities, benchmark with peer hospitals, and objectively monitor and assess hospital performance. In essence, Six Sigma can take TQM to the next level, a level focused on process improvement in quality and service.

Mosadeghrad [6] want to explore the barriers to TQM successful implementation in the healthcare sector and what are the major reasons for the failure of TQM programs in healthcare organizations. The author found that TQM implementation and its impact depend heavily on the ability of managers to adopt and adapt its values and concepts in professional healthcare organizations. Unsuccessful TQM efforts in healthcare organizations can be attributed to the strongly departmentalized, bureaucratic and hierarchical structure, professional autonomy, tensions between managers and professionals and the difficulties involved in evaluating healthcare processes and outcomes. Other obstacles to TQM success include lack of consistent managers' and employees' commitment to and involvement in TQM implementation, poor leadership and management, lack of a quality-oriented culture, insufficient training, and inadequate resources.

Finally, Jackson [7] recognizes that many total quality management initiatives fail and that the failures are often due to a lack of knowledge, skills and expertise, particularly in 
relation to the organization's leaders/managers. In contrast however, success is more likely if the implementation approach is well planned, executed, assessed and reviewed. There are five key steps that need to be contained within the implementation plan some of which include setting up a steering committee, agreeing the norms, values and behaviors for the organization and determining indicators associated with success. Furthermore, a number of actions need to be effected within those five key steps. In essence it was concluded that without careful planning the program for implementing total quality management was likely to fail resulting in an opposite effect on the quality of healthcare delivery to the one that was intended.

\section{PROBLEM STATEMENT}

TQM is about managing any organization to make it exceed in all important dimensions to the customer. Continuous improvement, teamwork, and a customer focus are required from the entire organization to ensure the success if the TQM approach. TQM was the choice of the managers for approximately two decades. However, in the beginning and mid of 1990, articles and people began to ask about the value and effectiveness of the TQM for number of organizations [4]. According to Chang in 1993, the primary reason of organization's failure was the implementing wide range of activities without focusing on the achieved results.

According to the authors in $[8,9,10]$, the followings are some of the reasons that made the use of the TQM to be declined: the need of more commitment and participation from the senior management, lack of clear planning along with the vision due to the overlapping duties of the leadership, change resistance, inadequate resources available which lead to the acceptance of any quick fix, excess work, more customer orientation is needed, the need of more education sessions for the comprehensive quality improvement, increase the level of people involvement, the shortage of accepted and accurate definition TQM components, accepting customer satisfaction may led to impede exceeding the satisfaction of the customers, finally, the shortage of clarity in the measurements and the shortage of real business measurable.

Furthermore, more reasons were been added by Harari in 1997 and they were: shifting the focus to the internal processes over the external results, concentrating on minimum number of standards, cumbersome bureaucracy being developed by TQM, delegating quality to quality experts instead of real people, TQM does not focusing on radical organizational reform and changes in management compensation as well as forming new relationships with outside partners, faddism, finally, the entrepreneurship and innovation are excluded from the TQM corporate culture [11].

Finally, the capital accumulation of pressures along with the structure of the hierarchical power restrict the effectiveness of the TQM along with the gap between what adopted by the TQM practitioners and what was actually being implemented. Many of TQM failures perceived from the improper implementation of the TQM principles and to the wrong promises and the desire of immediate achievements without patience $[12,13]$.

\section{EMERGENCE OF THE SIX SIGMA}

The beginning of the Six Sigma approach was as an improvement of the processes or a process's design goal pointed in normal distribution's properties terms. For enhancing and improving the quality, a lot of efforts were made to grantee 3.4 and less DPMOs (defects per million opportunities) may happens for any given process. It was clear that the quality relying on the several participation of functional areas, common metric presented by the Six Sigma on what efforts of other functions may be aligned.

Separate functions of an organization are distinguished by agendas, various outlooks, and approaches which provided quality initiatives resistance when the boundaries of the organization were crossed. In addition, Six Sigma expanded into assuring the success of the cross-functional quality improvement. Business leaders nowadays are thinking of it as a new way to gaining more revenues by current processes improvements [14].

\subsection{Factual Management}

Many quality controls tools along with different statistical methods are used in TQM for evaluating and improving quality. For example, for making sure of the sustainability of the quality improvement initiatives, Key performance indicators (KPIs) are used for this purpose. Six Sigma is a data oriented approach, selecting the key processes of the output variables as primary project metrics. Starting with the measure step of the Six Sigma keep track of the key variables over time. This will lead to the next step for applying various statistical techniques to analyze the root factors causing a process to vary in quality. Finally, the improve step decides what should be done for reducing the variability and to keep consistent results in the future.

This process is termed as DMAIC (Define, Measure, Analyse, Improve and Control). In the measure step it includes the following tools such as "process maps, Pareto charts, Cause and Effect diagrams, histograms, and capability ratios". In the analyse step, methods are "F-test, t-test, multi-variance, chi square, Mood's median, regression, Kruskal-Wallis, interactive plots, and Mann-Whitney". Finally, improve step include "mistake proofing, design-of-experiment, process modelling, response surface diagram, process capability, and main effects plot". Not all tools are used for every project. However, for selecting and applying the correct tools, extensive level of training must be done. Each tool is unique to an organization.

\subsection{Rational Leadership}

Leadership does not own one-size-fits-all definition. (Baldrige, 2002) defined leadership system as how leadership is exercised formal or informal way, within organization policies, rules, and procedures. Making decision, communicating, re-enforcement of organization values, directing employees, encouraging ethical behavior, selecting and developing leaders and employees is the key base of any leadership system.

In leadership, the capability of workforce and stakeholders must be respected. Teams are built in term of loyalty and towered organization's vision and values and the ability to pursuit straight for the sake of shared goals. It also encourages risk taking under appropriate level and avoids management that involves chains of command. It includes the process of self-examination, receive feedback, and improve of leaders.

Although various definitions of leadership among organization and industries exist, there was strong agreement of it importance by the top management in TQM. There is strong mutual correlation between six sigma and leadership. Leadership is the prime factor for a successful implementation of Six Sigma in an organization [15]. Six sigma drives more accurate result and thus allow good quality decision from top 
management level. The data-driven decision making concept is at the heart of the Six Sigma [16].

Despite the importance of leadership, the need of using techniques and methods to drive accurate result to perform good quality decision is equally important. A business success depends on the quality and speed of making decisions. Good decisions leads to improvement in the performance of an organization. Six Sigma expose unpredictable root causes of certain problem. It is be able to develop and build solutions that can reach to the core of the problem [17]. This solution help to provide leaders with quick fix to a problem within short period of time. Therefore, helps to address critical challenges and achieve strategic goals and objectives within an organization.

Decision-making is a vital part of the business world even for low-level leaders or managers. Making several decisions in a work day, and with some companies is critical to organization success.

\subsection{Continual Improvements - Kaizen}

Improvement of process takes place at different level of management in an organization. In the operational level, the focus is on improving the process and it is based on small incremental changes in nature. So, this approach is designed to have a cumulative effect on the process over a period of time. In this approach the engagement of workforce is important that creates ownership of process. However, this is not the only approach that takes place in the organization. The need for continuing the improvement of process appears in the organization's tactical level. At this level, the focus is on the improvement of individual process designed in order to achieve goals of an organization by step by step continuous improvement. An important point is that the continuous improvement of a process exists at the organization's second level and it is designed to increase the rate of improvement in the each of processes. Process improvement also occurs in strategic level, as well. As process become age or obsolete, the responsibility of management to improve or replace the process becomes critical. At this level radical changes of process within organization will take place in order to meet customer requirement. [18]

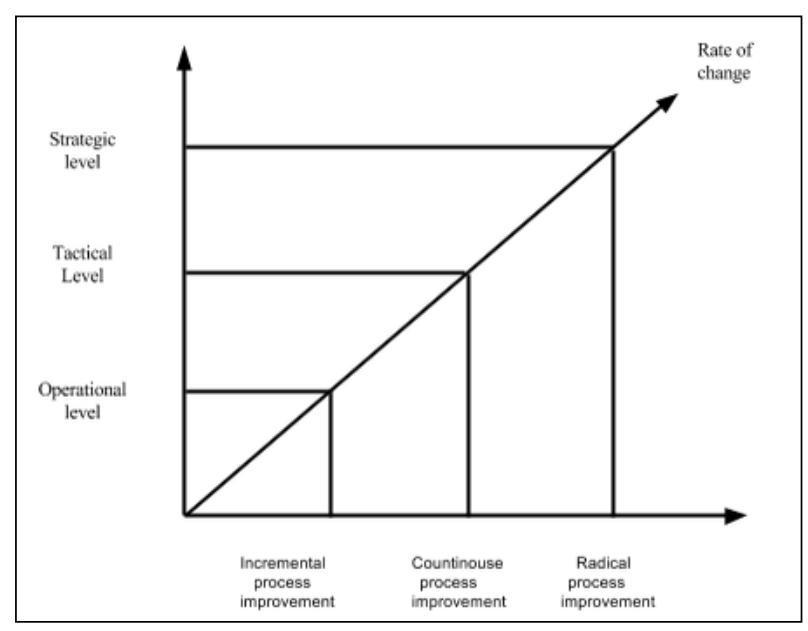

Figure 1: Degree of changes in organization level [18]

Six sigma continuous process improvements vary in the way of implementation. It can be implemented within management level. Also, can be used base on the organization strategy.
Six sigma can contribute in organization strategy in a wide range of ways. Focusing on financial measures, as the first approach was used by many companies in the past. The new trend is focusing on development of the organization capacity for enhancement and improvements through the Six Sigma delivers significantly more organizational benefit. However, it requires a total cultural transformation [19].

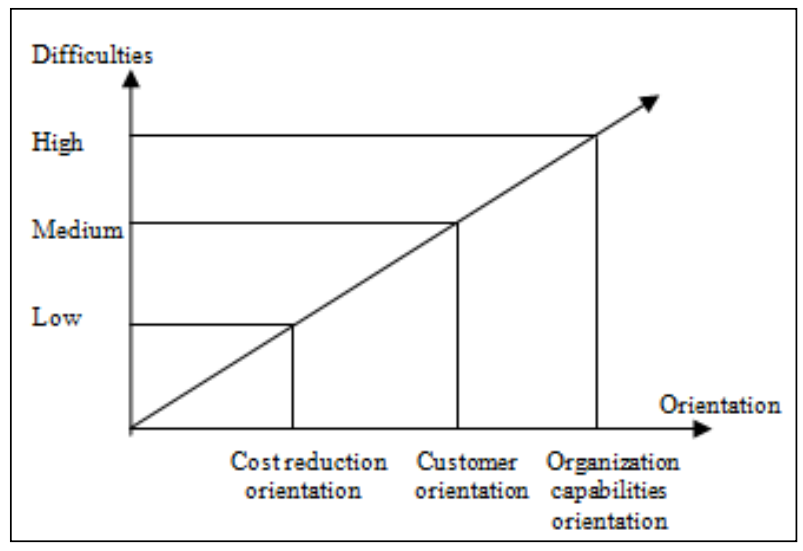

Figure 2: Degree of difficulties [19]

Figure 2 shows the implications of using six sigma are changes in the organizational culture, moving toward highest quality of expectation, which will drive employees and all stakeholders to passion for continuous improvement.

\subsection{Employees Partnership}

Measuring and managing quality can be easy in some organizations and very hard in others. Measuring and managing the quality is not good to be performed by Businesses, they aren't especially good at the quality for those processes, in other words, for most of the work done by nonmanufacturing businesses and units [20].

When an organization is think of improve its operational efficiency and raising the productivity at lower cost, then human resources are involved across all the levels in the organization to deploy this key business strategy. This is necessary as it require a cultural change.

For implementing the Six Sigma successfully in an organization, there are some sequential steps for the deployment as the following:

\subsubsection{Team formation}

To ensure the leader of quality movement across the entire organization, Commitment from the top management is very important. Criticality of management support is essential in handling obstacles with regard into the budget and resource allocation of the project.

Deploying the Six Sigma requires a set of a skilled professionals to guide the organization for higher maturity levels. In 1999, ASA Quality and Productivity Research Conference committee defined the Six Sigma professional roles are as the following:

- Master Black Belts (MBBs) are the quality leaders group responsible for setting the strategy, the training sessions, mentoring the employees, and deployment of Six Sigma.

- Black Belts are the experts in highly advanced Six Sigma statistical tools, they work on projects across the business functions. 
- Green Belts are quality professionals in Six Sigma non statistical tools but in part-time, they work on projects in their job.

\subsubsection{The Training}

In an organization, business leaders shall working with the Black Belts for identifying the correct resources from their functions along with the ability to handle business opportunities. The MBB are taking care of handling the design of the curriculum for the training programs. Personnel are getting trained by the Black Belts from operations on different Six Sigma levels programs.

\subsubsection{Idea Generation and Evaluation}

Six Sigma deployments has an important step which is the Ideation of different business opportunities. Workshops and work-out sessions are created. Black Belts and business leaders together create a comprehensive list of the provided ideas based on several sources. Organizational metrics scorecards highlight weekly performing metrics for improvement. Another opportunities for projects come from functional metric dashboards, leadership goals, business scorecards, brainstorming, process health check-ups, and process risks. Whenever the project list is prepared, the projects are grouped into different buckets for project methodology, governance, and timelines.

Ideas are evaluated on the basis of scope, estimated benefit, criticality to business, and complexity of the situation because not all of them are qualified as a Six Sigma project. The classification of Six Sigma projects is based on business impart and knowledge of the solution/improvement.

\subsubsection{Project Execution}

Black Belts are help assign the projects of the Six Sigma to the trained resources from operations. Yellow Belt projects can take from two to three months for completion. Green Belt projects may take from six-to-eight months, based on the data availability and root causes complexity of the problem. Black Belt projects are on an average take six to a year for completion. Based on the Six Sigma methodology, each improvement project takes either the DMAIC or DMADV roadmap to proceed. The employees are mentored from initiation until the completion of project by the Black Belts until the result is achieved. This uniqueness of this mentoring feature in Six Sigma is helping leaders of the projects to achieve confidence and support in delivering the projects.

\section{CONCLUSION}

Six sigma methodology have been adopted by many companies such Motorola, GE and other pioneers. These leading companies had a remarkable success because of following the customer oriented approach. When company follow customer oriented approach where it places customer satisfaction at the core of each decision it takes. Customer oriented means [21] "commitment taken by an organization to meet and exceed its customer expectation regarding services or product quality, and constantly evaluating and improving its internal process to meet customer expectations, by involving their employee to build valued relationship with their customer".

As the foundation of Wal-Mart Sam Walton says: "There is only one boss. The customer. And he can fire everybody in the company from the chairman on down, simply by spending his money somewhere else."[22]

Many organizations have set their strategy to customer orientation approach in order to gain competitive advantage in the market place. Other companies had set Six Sigma first objective based on cost reduction, not realizing that what deliver profitability for any organization in the long-term is satisfied customers, even more than low cost of services or products [23]. A good six sigma methodology basically focus on customer instead of the product or short term financial gain [24].

This strategy can be easily achieved by empowering and providing training to employees and stakeholders on how to use six sigma effectively and efficiently in order to improve internal processes to meet customer expectation. Moreover, training employee to build valued relationship with the customer is vital. All employees in the organization irrespective of their position must understand that their work contribution and what they need to do impress each customer [21].

This boundary-spanning role used by frontend employees helps the organization to gather information of related problem and pass it to backend employees to analyze it using techniques and tools, six sigma, to improve certain or several processes and then delivering good quality services or product that meets the customer expectation. So, it requires management empowering staff to use a wider range of individual initiatives to solving customer problems. These services provided by the company impacts a customer's perception of the company's dedication to customer.

\section{FUTURE WORK}

To implement customer-oriented approach, pioneers followed four major steps in order to achieve this goal. The steps as follow:

1. Identify what my customer need, his satisfaction.

2. Identify the gap between what the customer needs and what the organization provide wither product or services.

3. Define the reasons for this gap.

4. Identify the appropriate methods to action.

Following this approach helps the organization in many ways such as mistakes removals and elimination, product quality improvement, and the most important is products innovation.

\section{REFERENCES}

[1] P. Asubonteng, K. Mccleary, G. Munchus, " The evolution of quality in the US health care industry: an old wine in a new bottle," International Journal of Health Care Quality Assurance, Vol. 9, no. 3, pp. 11-19, 1996.[IEEE]. ProQuest Central:http://search.proquest.com/docview/229614217? accountid=142908. [Accessed March 8, 2015]

[2] K. Udayai and P. Kumar, Implementing Six Sigma to Improve Hospital Discharge Process, International Journal of Pharmaceutical Science and Research Vol. 3, Issue 11, 2012.

[3] Pande P S, Neuman R P and Cavanach R R (2000), The Six Sigma Way, McGraw-Hill, New York.

[4] A. S. Khandekar and V. N. Sulakhe, SIX SIGMA - THE REVIVAL OF TQM, International Journal of Mechanical Engineering and Robotics Research, Vol. 3, No. 1, P:50-58, 2014. 
[5] L. Revere and K. Black, Integrating Six Sigma with Total Quality Management: A Case Example for Measuring Medication Errors, Journal of healthcare management / American College of Healthcare Executives, Vol. 48, Issue 6, 2003.

[6] Ali Mohammad Mosadeghrad, (2013) "Obstacles to TQM success in health care systems", International Journal of Health Care Quality Assurance, Vol. 26 Iss: 2, pp. $147-173$

[7] S. Jackson, (2001),"Successfully implementing total quality management tools within healthcare: what are the key actions?", International Journal of Health Care Quality Assurance, Vol. 14 Issue 4 pp. 157 - 163.

[8] Lakhe, R. R. \& Mohanty, R. P. (1994) Total Quality Management: concepts, evolution and acceptability in developing economies, International Journal of Quality and Reliability Management, 11(9), pp. 9-33.

[9] Macdonald, J. (1995) Total Quality Management: does it always work? In G. K. Kanji (Ed.) Proceedings of the First World Conference, pp. 26-38 (London: Chapman \& Hall).

[10] Kanji, G. K. (1995) Quality and statistical concepts, in: G. K. Kanji (Ed.) Total Quality Management: Proceedings of the First World Congress (Abingdon: Chapman \& Hall).

[11] Harari, O. (1997) Ten reasons TQM doesn't work, Management Review, January, pp. 38-44.

[12] Knights, D. \& McCabe, D. (1999) Are there no limits to authority?: TQM and organizational power, Organizational Studies, Spring, pp. 1-24. Available at: http://www.highbeam.com/doc/1G1-57816026.html

[13] Kolesar, P. J. (1995). Partial quality management: an essay, Production and Operations Management, 4(3), pp. 195-200.

[14] Pyzdek, T. (2000b) The six sigma revolution: why six sigma? Quality America. Available at: http://www.qualityamerica.com/knowledgecente/articles/ PYZDEKSixSigRev.html (accessed June 2004).

[15] Joel E. Ross;Susan Perry (1999). Total Quality Management: Text, Cases, and Readings. 3rd ed. USA: CRC Press. 568.

[16] Ian Cox; Marie A. Gaudard; Philip J. Ramsey; Mia L. Stephens; Leo Wright. (2009). Introduction . In: Visual Six Sigma: Making Data Analysis Lean. USA: John Wiley \& Sons. 504.

[17] Castillo, Raul A. (2005). Six Sigma-Problem-Solving that Lasts. National Association of Corrosion Engineers. 44 (12), 8 .

[18] Merle E. Davis (2006). Continuous Improvement and Return on Investment: A Case Study to Determine the Value of Continuous Improvement in a Manufacturing Facility. USA: ProQuest. 122.

[19] Graeme Knowles (2012). Profit From Six Sigma. USA: Bookboon. 73.

[20] Fleming, J.M.; Coffman, C.; Hartner, J.K., "Manage your human sigma," Engineering Management Review, IEEE , vol.34, no.1, pp.52,52, First Quarter 2006, doi: 10.1109/EMR.2006.1679076

[21] Graeme Knowles (2012). Profit From Six Sigma. USA: Bookboon. 73

[22] Kim Lachance Shandrow. (OCTOBER 09, 2008). Sam Walton. Available: http://www.entrepreneur.com/article/197560. Last accessed March 23, 2015.

[23] Douglas, P. C., \& Erwin, J. (2000). Six sigma's focus on total customer satisfaction. The Journal for Quality and Participation,23(2), 45-49. Retrieved from http://search.proquest.com/docview/219132109?accounti $\mathrm{d}=142908$

[24] F. Ray Miller, Laura E. Miller (2007). That's Customer Focus!. USA: booksurge. 196 